\title{
Networked Life
}

\author{
Richelle E. Gribble
}

Richelle Gribble Studio, Los Angeles, CA, USA

Correspondence to: Richelle E. Gribble. 4091 Redwood Ave. Apt. 401, Los Angeles, CA, USA. Email: richellegribble@gmail.com.

Submitted Jan 08, 2019. Accepted for publication Feb 15, 2019.

doi: $10.21037 /$ cdt.2019.02.07

View this article at: http://dx.doi.org/10.21037/cdt.2019.02.07

Select works are part of a 365-day art project, Networked Life. For 1 year, I created an artwork every day in response to a network seen, experienced, or imagined. Works were mixed media and diverse, featuring paintings, drawings, sculptures, and found materials. This project provided an opportunity to examine networks across industries and disciplines, referencing both literal and abstract forms of networks. Each artwork contained hubs and links, clustering, and radial and tree-like branches.

Some networks were more obvious like a television network, a social media diagram, veins on a leaf, neural pathways, freeway systems, the Internet, and more, while others replicated the characteristics and structural properties of networks. Such abstract networks featured tessellations, fractals, lines and nodes, swarms, and other intricate web-like designs. My goal was to more closely understand the repeating patterns and similarities between diverse networks, providing insights regarding biological

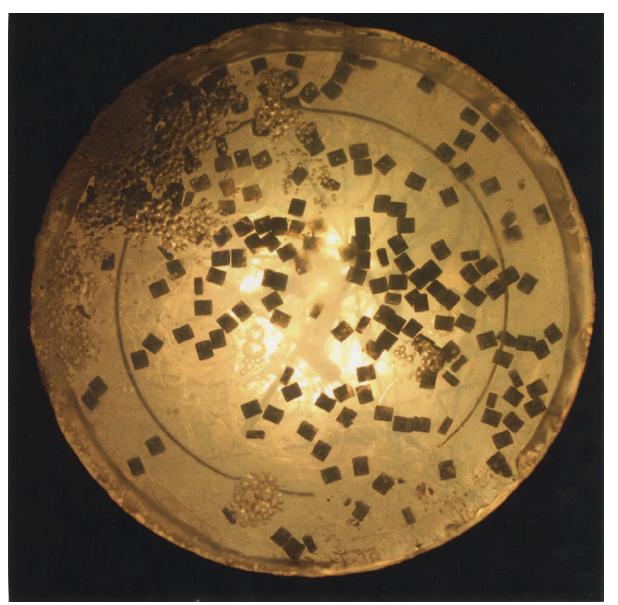

Figure 1 Networked Life: day 89, resin and resisters, 6 inches $\times 6$ inches, 2013. and technological connectivity.

The four images below are intended to reference microorganisms under a microscope (Figures 1-4). Yet, rather than illustrating a population of a particular living system, I used circuit resisters to reference the micro-life of technology within a petri dish. Like a buzzing cluster of plankton, these circuit board pieces gathered to form populated networks. These are visual, playful experiments of how entities organize within groups. By using resin, electrical components, and a light source, I made a series of imagined techno-species swimming under a microscope.

Networked Life culminated into a large-scale interactive puzzle containing hundreds of networks. Viewers were invited to make their own visual and thoughtful connections between networks, moving about interchangeable artworks into new formations. This puzzle activates a social network of participants to build a visual network of networks, together. Watch here: https://vimeo.com/90055564.

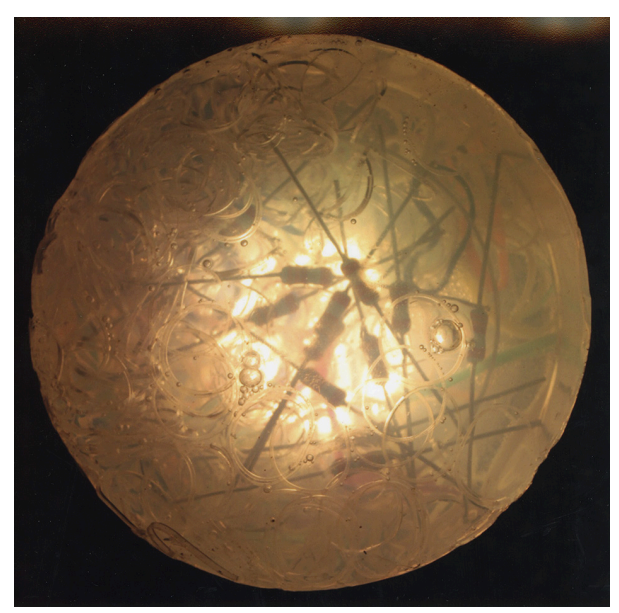

Figure 2 Networked Life: day 90, resin and resisters, 6 inches $\times 6$ inches, 2013. 


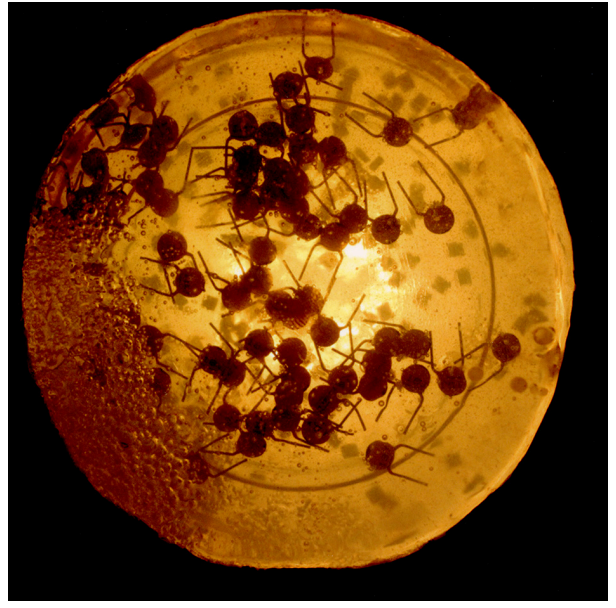

Figure 3 Networked Life: day 93, resin and resisters, 6 inches $\times 6$ inches, 2013.

\section{Acknowledgments}

None.

Cite this article as: Gribble RE. Networked Life. Cardiovasc Diagn Ther 2019;9(Suppl 2):S434-S435. doi: 10.21037/ cdt.2019.02.07

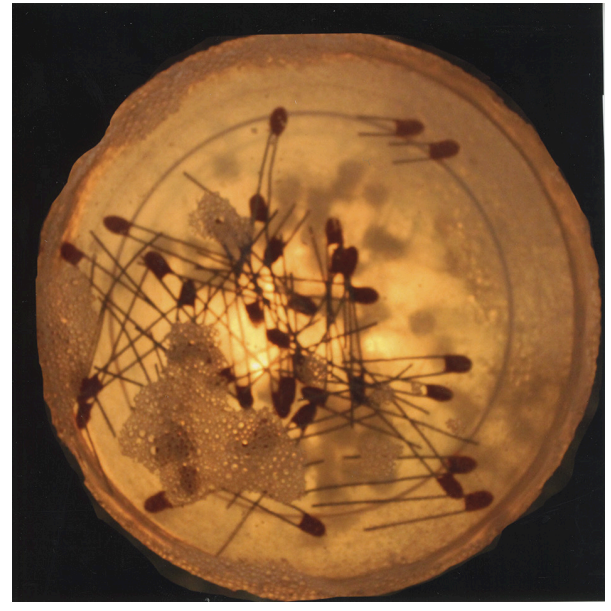

Figure 4 Networked Life: day 97, resin and resisters, 6 inches $\times 6$ inches, 2013.

\section{Footnote}

Conflicts of Interest: The author has no conflicts of interest to declare. 